\title{
Up-conversion luminescence in germanate glass and double-clad optical fibre co-doped with $\mathrm{Yb}^{3+} / \mathrm{Eu}^{3+}$ ions
}

\author{
M. KOCHANOWICZ ${ }^{* 1}$, J. ZMOJDA ${ }^{1}$, T. RAGIN ${ }^{1}$, P. MILUSKI ${ }^{1}$, and P. JELEN ${ }^{2}$ \\ ${ }^{1}$ Bialystok University of Technology, Department of Power Engineering, Photonics and Lighting Technology, \\ ul. Wiejska 45 D, 15 -351 Bialystok, Poland \\ ${ }^{2}$ AGH University of Science and Technology, Faculty of Materials Science and Ceramics, \\ ul. Mickiewicza 30, 30-059 Krakow, Poland
}

\begin{abstract}
In the paper the analysis of up-conversion $(U C)$ luminescence in $0.5 \mathrm{Yb}_{2} \mathrm{O}_{3} /(0.25-1) \mathrm{Eu}_{2} \mathrm{O}_{3}(\mathrm{~mol} . \%)$ co-doped germanate glass and optical fibre has been investigated. Up-conversion emission of bands at 591, 616, 652, $701 \mathrm{~nm}$ to which correspond Eu ${ }^{3+}$ : ${ }^{5} D_{0} \rightarrow{ }^{7} F_{1},{ }^{5} D_{0} \rightarrow{ }^{7} F_{2},{ }^{5} D 0 \rightarrow{ }^{7} F_{3},{ }^{5} D_{0} \rightarrow{ }^{7} F_{4}$ transitions, respectively was obtained as a result of cooperative energy transfer between $\mathrm{Yb}^{3+}$ and $\mathrm{Eu}{ }^{3+}$ ions. The highest up-conversion emission $\left(\mathrm{Yb}^{3+} \rightarrow E u^{3+}\right.$ energy transfer efficiency $\left.\eta=24 \%\right)$ was obtained in $0.5 \mathrm{Yb}_{2} \mathrm{O}_{3} / 0.75 \mathrm{Eu}_{2} \mathrm{O}_{3}$ co-doped glass. Comparison of up-conversion and down-conversion luminescence spectra of bulk glass, glass fibre and different length double-clad optical fibre (up to $5 \mathrm{~m}$ ) showed subtle differences in shape of the spectrum. In comparison to down - conversion emission $\left(\lambda_{\text {exc }}=405 \mathrm{~nm}\right)$ main UC luminescence band is red-shifted by $2 \mathrm{~nm}$ and is characterized by $5 \mathrm{~nm}$ greater full - width half- maximum (FWHM).
\end{abstract}

Keywords: germanate glass, co-doped with $\mathrm{Yb}^{3+} / \mathrm{Eu}^{3+}$, optical fibre, up-conversion luminescence.

\section{Introduction}

Luminescence in a visible spectral range in rare earth's doped glasses and optical fibres have found a wide range of potential photonic applications, such as solid state lighting, fluorescence imaging, display monitors, solid compact lasers and, especially, light sources used in PDT (Photodynamic therapy) [1-5]. Due to activation of photosensitizers and "therapeutic optical window" efficient irradiation light sources in a wavelength range of 600-800 $\mathrm{nm}$ are especially desirable [6]. Nowadays, lasers and light emitting diodes are commonly used as PDT light sources. $\mathrm{Eu}^{3+}$ - doped optical fibres open new possibilities in construction irradiation light sources for PDT where problem coupling of a light source with an optical fibre was naturally solved. Visible emission in $\mathrm{Eu}^{3+}$ doped glasses and optical fibres can be realized in two ways: down-conversion $\left(\lambda_{\text {exc }}=\mathrm{UV}-405 \mathrm{~nm}\right)$ and up-conversion $\left(\lambda_{\text {exc }}=976 \mathrm{~nm}\right)$ in $\mathrm{Yb}^{3+} / \mathrm{Eu}^{3+}$ system [7-9]. Sensitization of $\mathrm{Eu}^{3+}$ ions by co-doping with $\mathrm{Yb}^{3+}$ ions enables to obtain visible emission under pumping by commercial high power $976 \mathrm{~nm}$ laser diodes but only materials with relatively low phonon energies enable an effective conversion of IR to VIS radiation. Among oxide glasses, germanate

\footnotetext{
*e-mail: m.kochanowicz@pb.edu.pl
}

glasses owing to their good capacity for dissolving lanthanides, chemical resistance, good mechanical properties, high thermal stability are good candidates for constructing optical fibres. Furthermore, low phonon energy $\left(\sim 850 \mathrm{~cm}^{-1}\right)$ results in longer lifetimes of the metastable energy levels, thus germanium-based glasses are suitable for the implementation of up-conversion schemes [10-16]. The up-conversion luminescence processes have been studied in $\mathrm{Yb}^{3+}$ $\mathrm{Eu}^{3+}$ ions also in glass-ceramics, as well as phosphors but not in germanate glasses and optical fibres $[17,18]$.

In the paper, the effects of optical pumping by a NIR diode-laser on up-conversion luminescence in germano-gallate glasses and double-clad optical fibre co-doped with $\mathrm{Yb}^{3+} / \mathrm{Eu}^{3+}$ have been investigated. Special attention has been paid to an analysis of difference in luminescence spectra of fabricated different optical structures: bulk glass, glass fibre and double-clad optical fibre.

\section{Experiment}

The glasses from molar system: $(74.5-\mathrm{x}) \mathrm{GeO}_{2}-15 \mathrm{Ga}_{2} \mathrm{O}_{3}-$ $10 \mathrm{BaO}-5 \mathrm{Na}_{2} \mathrm{O}-0.5 \mathrm{Yb}_{2} \mathrm{O}_{3} / \mathrm{xEu}_{2} \mathrm{O}_{3}$, where $\mathrm{x}=0 ; 0.25 ; 0.5$; 0.75 ; 1 ; were melted from spectrally pure $(99.99 \%)$ raw materials. The homogenized set was placed in a platinum crucible and melted in an electric furnace at the temperature 
of $1500^{\circ} \mathrm{C}$ for 30 minutes. The molten glass was poured out onto a brass plate and, then exposed to the process of annealing at $610^{\circ}$ for 12 hours. Homogenous and transparent glasses were obtained without visible effect of crystallization. In order to determine spectral properties a series of samples with the dimensions of $6 \times 6 \times 2 \mathrm{~mm}^{3}$ were prepared. The spectral transmission measurement within the range from 0.3 to $1.1 \mu \mathrm{m}$ was taken using Stellarnet Green - Wave spectrometer. The glass density was calculated using the method of hydrostatic weighing. The refractive index (@632.8 nm) was determined using a Metricon 2010 refractometer. The characteristic temperatures of the obtained glasses were calculated based on the measurement taken with a SETARAM Labsys thermal analyzer using the DSC method. FTIR spectra were recorded with a Bruker Company Vertex 70v spectrometer. Spectra were collected in the middle infrared regions (MIR) $1400-400 \mathrm{~cm}^{-1}$ after 128 scans at $4 \mathrm{~cm}^{-1}$ resolution. The luminescence spectra of glasses and optical fibre (end-face pumped) within the range of 300-750 nm were measured at a station equipped with a Stellarnet Green-Wave spectrometer and a pumping laser diode $\left(\lambda_{\text {exc }}=405\right.$ $\mathrm{nm}$ or $\lambda_{\text {exc }}=976 \mathrm{~nm}$ ) with a $0.5 \mathrm{~nm}$ resolution. A system PTI QuantaMaster QM40 coupled with tunable pulsed optical parametric oscillator (OPO), pumped by a third harmonic of a Nd:YAG laser (OpotekOpolette 355 LD) was used for luminescence decay measurements. The laser system was equipped with a double $200 \mathrm{~mm}$ monochromator, a multimode UV-VIS PMT (R928) and Hamamatsu H10330B-75 detectors controlled by a computer. Luminescence decay curves were recorded and stored by a PTI ASOC-10 (USB-2500) oscilloscope with an accuracy of $\pm 1 \mu \mathrm{s}$. The double-clad optical fibre with off-set of core was fabricated using a modified rod-in-tube technique. Core of the fibre was made by using crucible method. Next, $3 \mathrm{~mm}$ diameter hole was mechanically drilled in a lead-silicate glass cylinder - inner cladding $\left(30 \mathrm{~mm}\right.$ diameter, $\left.n_{\text {cladding } 1}=1.62\right)$. As an outer cladding was used a borosilicate glass tube $\left(n_{\text {cladding } 2}=1.51\right)$. Fibre was drawn at a temperature range of $850-920^{\circ} \mathrm{C}$. The diameter of the fibre was controlled by monitoring the drawing speed and the feeding of the preform.

\section{Results and discussion}

\subsection{Material and thermal properties}

Table 1 presents basic physicochemical and thermal properties of the produced $\mathrm{Yb}^{3+} / \mathrm{Eu}^{3+}$ co-doped germanate glasses.

The fabricated glasses are characterized by high thermal stability which determines their suitability as a material for the construction of optical fibres. A difference $\Delta T=T_{x}-T_{g}$ called glass thermal stability factor is determined to be
Table 1. Physical and thermal properties of $75 \mathrm{GeO}_{2}-25[\mathrm{GaO}-$ $\mathrm{BaO}-\mathrm{Na}_{2} \mathrm{O}$ ] glass.

\begin{tabular}{lc}
\hline \multicolumn{1}{c}{ Parameter } & Value \\
\hline Refractive index $n(@ 632.8 \mathrm{~nm})$ & 1.688 \\
Mass density $\rho\left(\mathrm{g} / \mathrm{cm}^{3}\right)$ & 4.4 \\
Transformation temperature $T_{g}\left({ }^{\circ} \mathrm{C}\right)(\mathrm{DSC})$ & 600 \\
Crystallization temperature $T_{x}\left({ }^{\circ} \mathrm{C}\right)(\mathrm{DSC})$ & 810 \\
Maximum of phonon energy $h \omega_{\max }\left(\mathrm{cm}^{-1}\right)$ & 805 \\
\hline
\end{tabular}

$210^{\circ} \mathrm{C}$. Moreover, relatively low phonon energy $\left(805 \mathrm{~cm}^{-1}\right)$ enables to effective IR to VIS conversion.

\subsection{Up-conversion luminescence and analysis of cooperative energy transfer}

Figure 1 presents up-conversion emission spectra of fabricated germanate glasses co-doped with $\mathrm{Yb}^{3+} / \mathrm{Eu}^{3+}$ ions under excitation by the diode laser with $\lambda_{\text {exc }}=976 \mathrm{~nm}$ and the optical pump power $P_{e x c}=1 \mathrm{~W}$. The concentration of $\mathrm{Yb}_{2} \mathrm{O}_{3}$ was fixed at $0.5 \mathrm{~mol} \%$.

The measured up-conversion spectra consist of emission bands at 591, 616, 652 and $701 \mathrm{~nm}$, which correspond to $\mathrm{Eu}^{3+}:{ }^{5} \mathrm{D}_{0} \rightarrow{ }^{7} \mathrm{~F}_{1},{ }^{5} \mathrm{D}_{0} \rightarrow{ }^{7} \mathrm{~F}_{2},{ }^{5} \mathrm{D}_{0} \rightarrow{ }^{7} \mathrm{~F}_{3}$ and ${ }^{5} \mathrm{D}_{0} \rightarrow{ }^{7} \mathrm{~F}_{4}$ transitions, respectively. In fabricated glasses the local symmetry of the RE ion site parameter R defined as the intensity ratio of $\mathrm{I}_{616 \mathrm{~nm}} / \mathrm{I}_{591 \mathrm{~nm}}$ is c.a 3 which indicates that the $\mathrm{Eu}^{3+}$ ion site has no inversion centre $[19,20]$. The maximum intensity of up-conversion luminescence was obtained with the concentration ratio of $0.5 \mathrm{Yb}_{2} \mathrm{O}_{3} / 0.75 \mathrm{Eu}_{2} \mathrm{O}_{3}$. Above $1.25 \mathrm{~mol} \%$ of $\mathrm{RE}$ the intensity of up-conversion luminescence of all emission bands decreases due to concentration quenching. The possible up-conversion emission mechanism in a germanate glass co-doped with $\mathrm{Yb}^{3+} / \mathrm{Eu}^{3+}$ is presented in Fig. 1 (inset). Population of $\mathrm{Eu}^{3+}$ excited levels is realized in the course of known phenomenon cooperative energy transfer from pair $\mathrm{Yb}^{3+}$ ions [19] accordingly to following relation:

$$
2 \times \mathrm{Yb}^{3+}\left({ }^{2} \mathrm{~F}_{5 / 2}\right)+\mathrm{Eu}^{3+}\left({ }^{7} \mathrm{~F}_{0}\right) \rightarrow 2 \times \mathrm{Yb}^{3+}\left({ }^{2} \mathrm{~F}_{7 / 2}\right)+\mathrm{Eu}^{3+}\left({ }^{5} \mathrm{D}_{1}\right)
$$

It should be noted that emission at $531 \mathrm{~nm}$ corresponding to ${ }^{5} \mathrm{D}_{0} \rightarrow{ }^{7} \mathrm{~F}_{0}$ transition wasn't observed in the manufactured glass. Figure 2 shows the luminescence decays from the ${ }^{2} \mathrm{~F}_{5 / 2}$ state of $\mathrm{Yb}^{3+}$ ions excited under $976 \mathrm{~nm}$. Luminescence decay analysis clearly indicates that the measured lifetime starts to reduce from $984 \mu$ s $\left(0.5 \% \mathrm{Yb}_{2} \mathrm{O}_{3}\right)$ up to $712 \mu \mathrm{s}$ $\left(0.5 \% \mathrm{Yb}_{2} \mathrm{O}_{3} / 1 \% \mathrm{Eu}_{2} \mathrm{O}_{3}\right)$. Decay curve given in semi-logarithmic scale is linear, which proofs single-exponential decay behaviour.

Based on luminescence decay measurements for ${ }^{2} \mathrm{~F}_{5 / 2}$ state of $\mathrm{Yb}^{3+}$ ions in glass samples without and with $\mathrm{Eu}^{3+}$ 


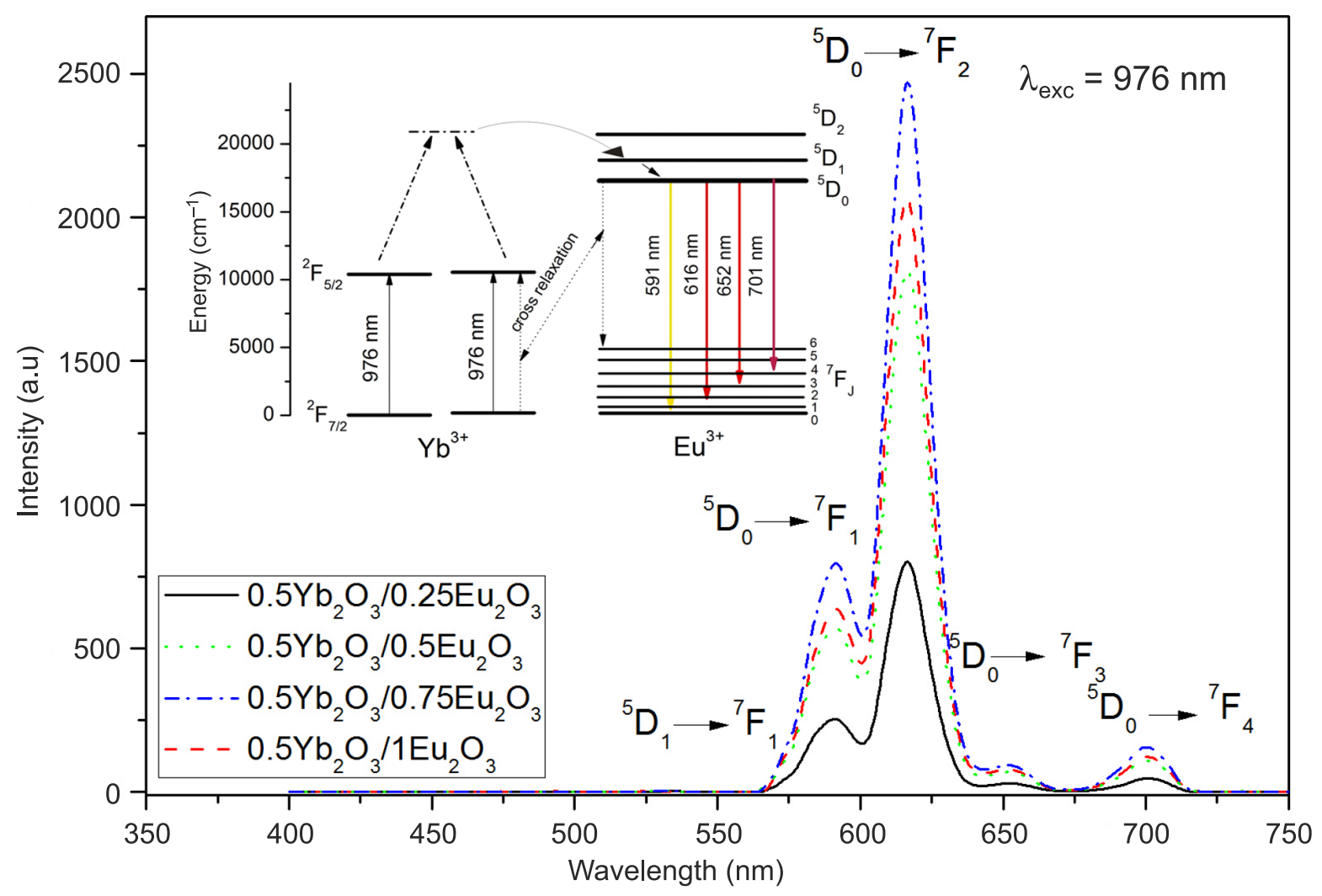

Fig. 1. Up-conversion luminescence spectra of $\mathrm{Yb}^{3+} / \mathrm{Eu}^{3+}$ co-doped germanate glasses $\left(\lambda_{\text {exc }}=976 \mathrm{~nm}\right)$.

ions, the $\mathrm{Yb}^{3+} \rightarrow \mathrm{Eu}^{3+}$ energy transfer efficiency was determined. Dependence of ${ }^{2} \mathrm{~F}_{5 / 2}\left(\mathrm{Yb}^{3+}\right)$ lifetime and the energy transfer efficiency with europium concentration is presented in Table 2. Efficiency of the $\mathrm{Yb}^{3+} \rightarrow \mathrm{Eu}^{3+}$ energy transfer can be calculated according to the equation

$$
\eta=1-\frac{\tau_{Y b}^{Y b-E u}}{\tau_{Y b}}
$$

where: $\tau_{Y b}^{Y b-E u}, \tau_{Y b}$ - lifetime of ${ }^{2} \mathrm{~F}_{5 / 2}$ state in $\mathrm{Yb}^{3+} / \mathrm{Eu}^{3+}$ co-doped and $\mathrm{Yb}^{3+}-$ singly doped sample, respectively. Efficiency of cooperative $\mathrm{Yb}^{3+} \rightarrow \mathrm{Eu}^{3+}$ energy transfer increases with increasing $\mathrm{Eu}^{3+}$ concentration up to $\eta=27 \%$ for $1 \% \mathrm{Eu}_{2} \mathrm{O}_{3}$, while maximum $\mathrm{UC}$ intensity due to concentration quenching was obtained in $0.5 \mathrm{Yb}_{2} \mathrm{O}_{3} / 0.75 \mathrm{Eu}_{2} \mathrm{O}_{3}$ co-doped glass.

Table 2. Lifetime of $\mathrm{Yb}^{3+}:{ }^{2} \mathrm{~F}_{5 / 2}$ level and ET efficiency in glasses co-doped with $0.5 \mathrm{Yb}_{2} \mathrm{O}_{3} /(0-1) \mathrm{Eu}_{2} \mathrm{O}_{3}$.

Content of $\mathrm{Eu}_{2} \mathrm{O}_{3} \quad$ Lifetime $\mathrm{Yb}^{3+}:{ }^{2} \mathrm{~F}_{5 / 2}$ ( $\mu$ s) $\quad$ ET efficiency (\%)

\begin{tabular}{ccc}
0 & 984 & 0 \\
0.25 & 953 & 3.15 \\
0.5 & 869 & 11.67 \\
0.75 & 744 & 24.39 \\
1 & 712 & 27.64 \\
\hline
\end{tabular}

\subsection{Double clad optical fibre co-doped with $0.5 \mathrm{Yb}_{2} \mathrm{O}_{3} / 0.75 \mathrm{Eu}_{2} \mathrm{O}_{3}$}

Basic parameters of the produced optical fibre were as follows: outer cladding diameter $=300 \mu \mathrm{m}$, core diameter $=$ $20 \mu \mathrm{m}$, core - offset $=70 \mu \mathrm{m}, N A_{\text {cladding }}=0.58, N A_{\text {core }}=$ 0.44 . Measured by the cutback method ASE signal attenuation at $616 \mathrm{~nm}$ is $2.18 \mathrm{~dB} / \mathrm{m}$ (Fig. 4 - inset) and it is lower

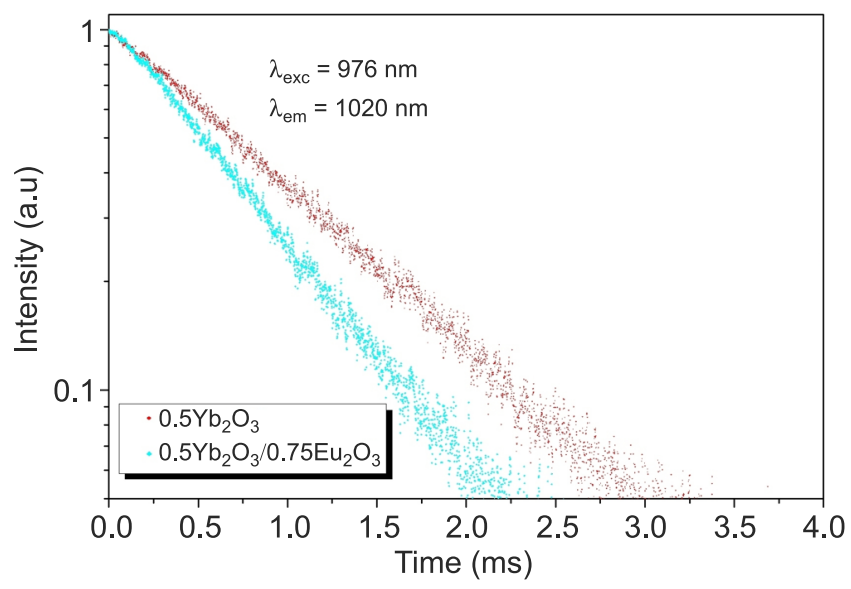

Fig. 2. Luminescence decay curves of $\mathrm{Yb}^{3+}:{ }^{2} \mathrm{~F}_{5 / 2}$ level in glasses co-doped with, $0.5 \mathrm{Yb}_{2} \mathrm{O}_{3} /(0,0.75) \mathrm{Eu}_{2} \mathrm{O}_{3}$. 


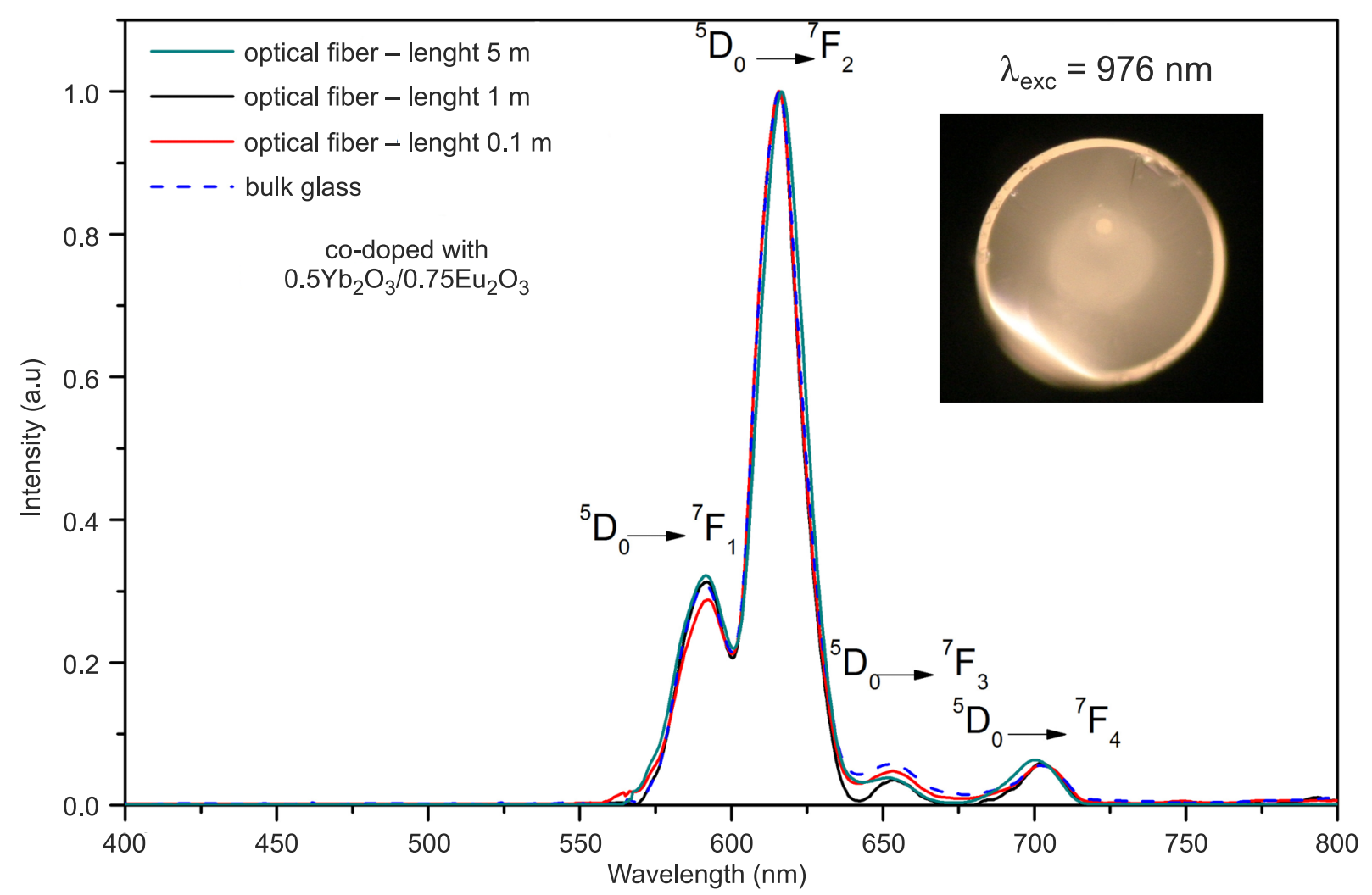

Fig. 3. Comparison of the luminescence spectra of bulk glass (further fibre core) and DC optical fibre (length of 0.1-5 m) co-doped with 0.5 $\mathrm{Yb}_{2} \mathrm{O}_{3} / 0.75 \mathrm{Eu}_{2} \mathrm{O}_{3}[\mathrm{~mol} \%]$. (Inset) Cross - section of the end face of the optical fibre.

than in a tellurite and fluoro-germanate optical fibre [21,22]. Due to helical modes of pump radiation offset of the core from the centre of the fibre enables to improve efficiency of optical pumping of the double-clad optical fibre [23]. In the standard double - clad optical fibre a large amount of pump energy do not interact with the core. The possible solutions of that problem concern shaping of cladding or placing the active core with offset. Figure 3 shows normalized up-conversion luminescence spectra and cross-section of the end face of the fabricated bulk glass (further fibre core) and double-clad optical fibre co-doped with $0.5 \mathrm{Yb}_{2} \mathrm{O}_{3} / 0.75 \mathrm{Eu}_{2} \mathrm{O}_{3}$.

While analysing UC emission of different length of DC optical fibre with bulk glass (further core) significant differences were not observed. $\mathrm{I}_{616 \mathrm{~nm}} / \mathrm{I}_{591 \mathrm{~nm}}$ luminescence intensity ratio (Fig. 4) remains nearly unchanged. In comparison to $\mathrm{Yb}^{3+} / \mathrm{Ho}^{3+}$ or $\mathrm{Yb}^{3+} / \mathrm{Tm}^{3+}$ co-doped optical fibres where reabsorption of ASE (amplified spontaneous emission) signal affecting the shape of emission spectra takes place, in a produced $\mathrm{Yb}^{3+} / \mathrm{Eu}^{3+}$ - co-doped DC fibre this phenomenon does not occur $[22,24]$. However, in a glass fibre $(0.1 \mathrm{~m}$ length) UC emission at $616 \mathrm{~nm}\left({ }^{5} \mathrm{D}_{0} \rightarrow{ }^{7} \mathrm{~F}_{2}\right)$ becomes dominant $\left(\mathrm{I}_{616 \mathrm{~nm}} / \mathrm{I}_{591 \mathrm{~nm}}=4.17\right)$.

In this case all pump power is absorbed in a glass fibre structure at a short length, thus transition corresponding to the highest luminescence band branching ratio starts to be promoted during propagation along the fibre. Figure 5 enables detailed comparison of the down-conversion $\left(\lambda_{e x c}=\right.$ $405 \mathrm{~nm})$ and up-conversion $\left(\lambda_{\text {exc }}=976 \mathrm{~nm}\right)$ luminescence obtained in the fabricated DC optical fibre co-doped with $0.5 \mathrm{Yb}_{2} \mathrm{O}_{3} / 0.75 \mathrm{Eu}_{2} \mathrm{O}_{3}$. Up-conversion emission band at 616 $\mathrm{nm}$ is slightly red-shifted by $2 \mathrm{~nm}$ and FWHM is $5 \mathrm{~nm}$ greater $(\mathrm{FWHM}=18 \mathrm{~nm})$ than in the same optical fibre $\mathrm{Eu}^{3+}$ ions directly excited by $405 \mathrm{~nm}$. Moreover, when visible emission is realized in course of UC process the $\mathrm{I}_{616 \mathrm{~nm}} / \mathrm{I}_{591 \mathrm{~nm}}$ intensity ratio is smaller and equals 3.4 while for $\lambda_{e x c}=$ $405 \mathrm{~nm}$ is 4.2. Moreover, in case of $\lambda_{\text {exc }}=405 \mathrm{~nm}$ the $\mathrm{I}_{616 \mathrm{~nm}} /$ $\mathrm{I}_{701 \mathrm{~nm}}$ intensity ratio is smaller. Calculated tri-chromatic coordinates (Fig. 5 inset) shows subtle differences in CIE 1931 triangle.

\section{Conclusions}

In the article thermally stable $\left(\Delta \mathrm{T}=210^{\circ} \mathrm{C}\right)$ and low phonon energy $\left(805 \mathrm{~cm}^{-1}\right)$ germanate glass co-doped with $\mathrm{Yb}^{3+} /$ $\mathrm{Eu}^{3+}$ ions were synthesized and used as the core of a double-clad optical fibre. The optimal concentration of rare-earths is $0.5 \mathrm{Yb}_{2} \mathrm{O}_{3} / 0.75 \mathrm{Eu}_{2} \mathrm{O}_{3}$ (mol.\%), which has shown the highest up-conversion emission intensity at $616 \mathrm{~nm}$ 


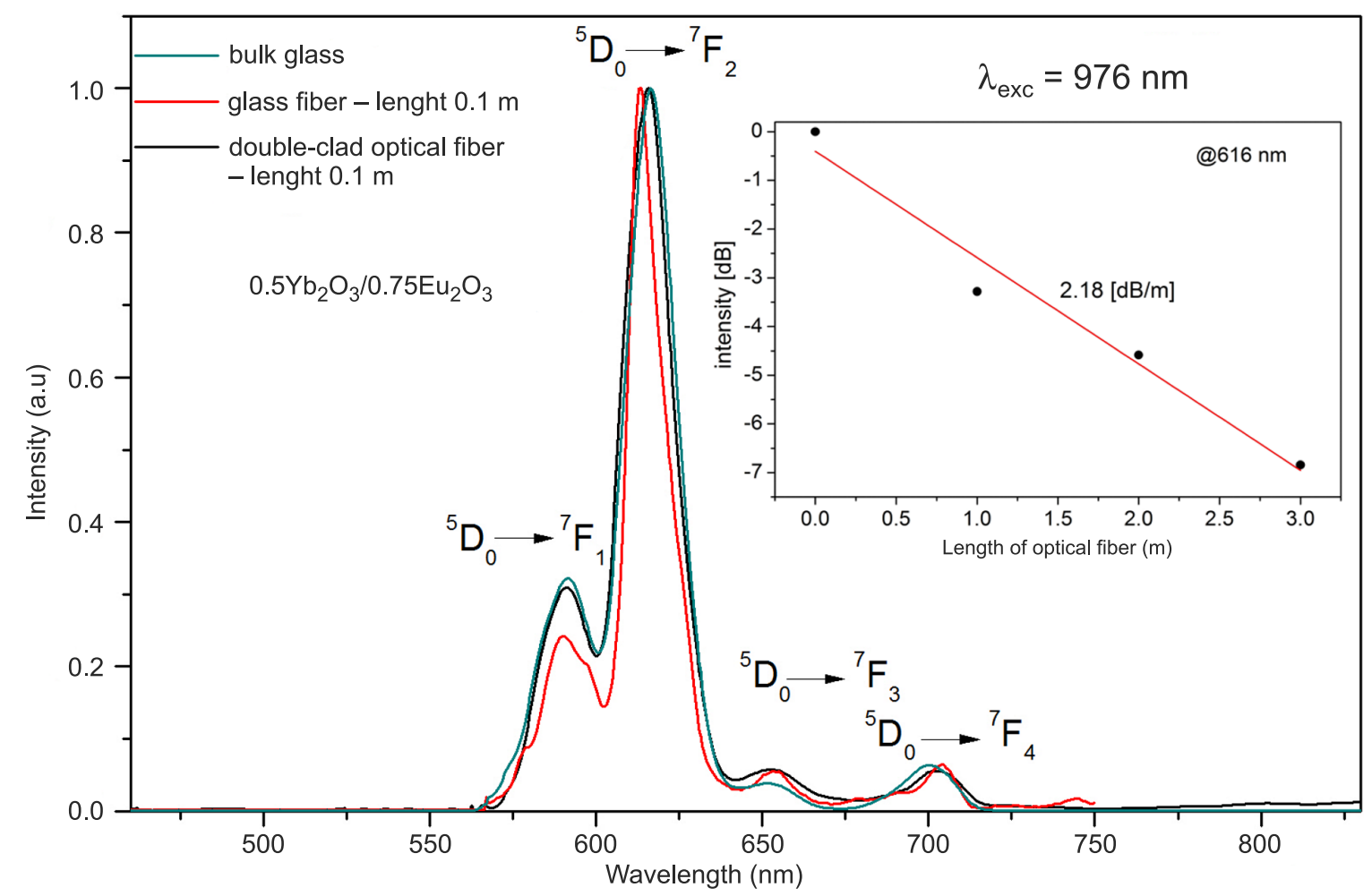

Fig. 4. Comparison of the up-conversion luminescence spectra of bulk glass (further fibre core), glass fibre and double-clad optical fibre (length $0.1 \mathrm{~m}$ ) co-doped with $0.5 \mathrm{Yb}_{2} \mathrm{O}_{3} / 0.75 \mathrm{Eu}_{2} \mathrm{O}_{3}[\mathrm{~mol} \%]\left(\lambda_{\text {exc }}=976 \mathrm{~nm}\right)$, ASE attenuation in DC optical fibre (inset).

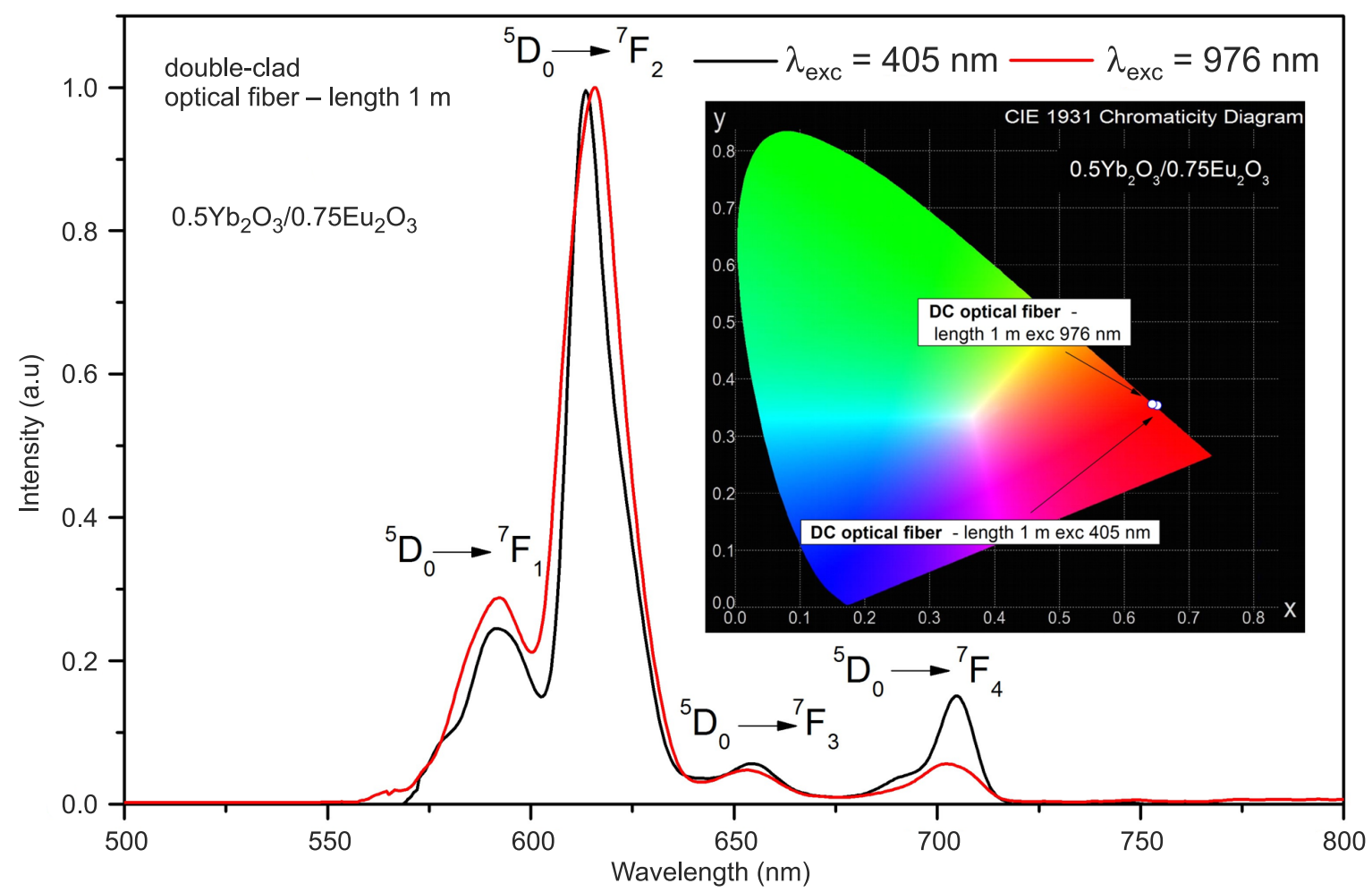

Fig. 5. Comparison of the luminescence spectra of double-clad optical fibre (length $1 \mathrm{~m}$ ) co-doped with $0.5 \mathrm{Yb}_{2} \mathrm{O}_{3} / 0.75 \mathrm{Eu}_{2} \mathrm{O}_{3}$ pumped by 405 $\mathrm{nm}$ and $976 \mathrm{~nm}, \mathrm{CIE}$ (x, y) chromaticity diagram - the colour coordinates of the luminescence (inset). 
$\left({ }^{5} \mathrm{D}_{0} \rightarrow{ }^{7} \mathrm{~F}_{2}\right)$ and $591 \mathrm{~nm}\left({ }^{5} \mathrm{D}_{0} \rightarrow{ }^{7} \mathrm{~F}_{2}\right)$ obtained as a $\mathrm{Yb}^{3+} \rightarrow$ $\mathrm{Eu}^{3+}$ cooperative energy transfer. Calculated on the basis of the analysis of the $\mathrm{Yb}^{3+}:{ }^{2} \mathrm{~F}_{5 / 2}$ level energy the maximum transfer efficiency is up to $27.6 \%$ for $0.5 \mathrm{Yb}_{2} \mathrm{O}_{3} / 1 \mathrm{Eu}_{2} \mathrm{O}_{3}$. Comparison of UC luminescence of bulk glass and different length of optical fibre (up to $5 \mathrm{~m}$ ) showed no significant differences in shape of the spectrum. However, in a glass fibre (0.1 m length) UC emission at $616 \mathrm{~nm}$ corresponding to ${ }^{5} \mathrm{D}_{0} \rightarrow{ }^{7} \mathrm{~F}_{2}$ transition becomes dominant. Comparative analysis of the down-conversion $\left(\lambda_{e x c}=405 \mathrm{~nm}\right)$ and up-conversion $\left(\lambda_{\text {exc }}=976 \mathrm{~nm}\right)$ luminescence obtained in the fabricated DC optical fibre co-doped with $0.5 \mathrm{Yb}_{2} \mathrm{O}_{3} / 0.75 \mathrm{Eu}_{2} \mathrm{O}_{3}$ showed subtle differences in shape of emission spectra. In relation to down - conversion emission $\lambda_{e x c}=405 \mathrm{~nm}$ main $\mathrm{UC}$ luminescence band is red-shifted by $2 \mathrm{~nm}$ and is characterized by $5 \mathrm{~nm}$ greater FWHM. The main advantage of UC mechanism in obtaining visible emission is possibility of pumping $\mathrm{Yb}^{3+} / \mathrm{Eu}^{3+}$ co-doped glasses and optical fibres by low cost, high power InGaAs laser diodes. However, it should be noted that $\mathrm{Yb}^{3+} \rightarrow \mathrm{Eu}^{3+}$ cooperative energy transfer is less efficient that other energy transfer mechanisms (e.g., up-conversion energy transfer) and requires low phonon glass host. To summarize, the obtained results show applicability of the produced germanate double-clad optical fibre co-doped with $0.5 \mathrm{Yb}_{2} \mathrm{O}_{3} / 0.75 \mathrm{Eu}_{2} \mathrm{O}_{3}$ in a construction of up-conversion superfluorescent optical fibre sources of radiation operating in the visible spectrum.

\section{Acknowledgements}

The project was funded by the National Science Centre (Poland) granted on the basis of the decision No. DEC-2013/ 09/D/ST8/03987.

\section{References}

1. D. Lande, S.S. Orlov, A. Akella, L. Hesselink, and R.R. Neurgaonkar, "Digital holographic storage system incorporating optical fixing", Opt. Lett. 22, 1722-1724 (1997).

2. P. Xie and T.R. Gosnell, "Room-temperature up-conversion fibre laser tunable in the red, orange, green, and blue spectral regions", Opt. Lett. 20, 1014-1016 (1995).

3. D.M. Costantini, H.G. Limberger, T. Lasser, C.A. P. Muller, H. Zellmer, P. Riedel, and A. Tünnermann, "Actively mode-locked visible up-conversion fibre laser”, Opt. Lett. 25, 1445-1447 (2000).

4. D.E.J.G.J. Dolmans, D. Fukumura, and R.K. Jain, "Photodynamic therapy for cancer", Nat. Rev. Cancer 3, 380-387 (2003).

5. A.P. Castano, P. Mroz, and M.R. Hamblin, "Photodynamic therapy and anti-tumour immunity", Nat. Rev. Cancer 6, 535-545 (2006).
6. R. Richards-Kortum and E. Sevick-Muraca, "Quantitative optical spectroscopy for tissue diagnosis", Annu. Rev. Phys. Chem. 47, 555-606 (1996).

7. C. Zhu, J. Wang, M. Zhang, X. Ren, J. Shen, Y. Yue, and J. Ballato, "Eu-,Tb-, and dy-doped oxyfluoride silicate glasses for LED applications", J. Am. Chem. Soc. 97, 854-861 (2014).

8. H. Zeng, Y. Yang, Z. Lin, X. Liang, S. Yuan, G. Chen, and L. Sun, "The effect of $\mathrm{B}_{2} \mathrm{O}_{3}$ on the luminescent properties of $\mathrm{Eu}$ ion-doped aluminoborosilicate glasses", J. Non-Cryst. Solids 357, 2328-2331 (2011).

9. G.S. Maciel, A. Biswas, and P.N. Prasad, "Infrared-to-visible $\mathrm{Eu}^{3+}$ energy up-conversion due to cooperative energy transfer from an $\mathrm{Yb}^{3+}$ ion pair in a sol-gel processed multi-component silica glass", Opt. Commun. 178, 65-69 (2000).

10. M. Cai, B. Zhou, Y. Tian, J. Zhou, S. Xu, and J. Zhang, "Broadband mid-infrared $2.8 \mu \mathrm{m}$ emission in $\mathrm{Ho}^{3+} / \mathrm{Yb}^{3+}$-codoped germanate glasses", J. Lumin. 171, 143-148 (2016).

11. M. Cai, B. Zhou, F. Wang, Y. Tian, J. Zhou, S. Xu, and J. Zhang, "Highly efficient mid-infrared $2 \mu \mathrm{m}$ emission in $\mathrm{Ho}^{3+} / \mathrm{Yb}^{3+}$-codoped germanate glass", Opt. Mat. Express 5, 1431 (2015).

12. X. Liu, B. Chen, E. Y. B. Pun, and H. Lin, "White up-conversion luminescence in $\mathrm{Tm}^{3+} / \mathrm{Ho}^{3+} / \mathrm{Yb}^{3+}$ triply doped $\mathrm{K}^{+}-\mathrm{Na}^{+}$ ion-exchanged aluminium germanate glass channel waveguide", Opt. Mat. 35, 590-595 (2013).

13. L.F. Shen, B.J. Chen, E.Y.B. Pun, and H. Lin, "Gain properties of the transition emissions near the second telecommunication window in $\mathrm{Ho}^{3+}$-doped multicomponent heavy-metal gallate glasses", J. Lumin. 132, 676-681 (2012).

14. M. Kochanowicz, D. Dorosz, J. Zmojda, J. Dorosz, J. Pisarska, and W.A. Pisarski", Up-conversion luminescence of $\mathrm{Tb}^{3+}$ ions in germanate glasses under diode-laser excitation of $\mathrm{Yb}^{3+}$, Opt. Mater. Express 4, 1050-1056 (2014).

15. W.A Pisarski, J. Pisarska, D. Dororsz, and J. Dorosz, "Rare earths in lead-free oxyfluoride germanate glasses", Spectrochim. Acta Mol. Biomol. Spectrosc. 134, 587-91 (2015).

16. R. Wang, Z. Yang, D. Zhou, Z. Song, and J. Qiu, "Structure and luminescent property of $\mathrm{Er}^{3+}$-doped germanate glasses", J Non-Cryst. Solids 383, 200-204 (2014).

17. A. Bahadur, Y. Dwivedi, and S. B. Rai, "Structural and spectroscopic diagnosis of Eu: $\mathrm{ZnO}$ and $\mathrm{Eu}: \mathrm{Yb}: \mathrm{ZnO}$ glass and ceramics", Spectrochim. Acta Mol. Biomol. Spectrosc. 91, 217-221 (2012).

18. X. Wei, J. Zhao, W. Zhang, Y. Li, and M. Yin, "Cooperative energy transfer in $\mathrm{Eu}^{3+}, \mathrm{Yb}^{3+}$ codoped $\mathrm{Y}_{2} \mathrm{O}_{3}$ phosphor", $J$. Rare Earth 28, 166-170 (2010).

19. P.A. Loiko, G.E. Rachkovskaya, G.B. Zakharevich, A.A. Kornienko, E.B. Dunina, A.S. Yasukevich, and K.V. Yumashev, "Cooperative up-conversion in $\mathrm{Eu}^{3+}, \mathrm{Yb}^{3+}$-doped $\mathrm{SiO}_{2}-\mathrm{PbO}-\mathrm{PbF}_{2}-\mathrm{CdF}_{2}$ oxyfluoride glass", J. Non-Cryst. Solids 392-393, 39-44 (2014).

20. K. Biswas, S. Balaji, D. Ghosh, A. D. Sontakke, and K. Annapurna, "Near-infrared frequency down-conversion and cross-relaxation in $\mathrm{Eu}^{2+} / \mathrm{Eu}^{3+}-\mathrm{Yb}^{3+}$ doped transparent oxyfluoride glass and glass-ceramics", J. Alloy Compd. 608, 266-271 (2014). 
21. R. Narro-García, E.F. Chillcce, L.C. Barbosa, E. de Posada, M. Arronte, and E. Rodriguez, "Fabrication and up-conversion luminescence of $\mathrm{Er}^{3+} / \mathrm{Yb}^{3+}$ codoped $\mathrm{TeO}_{2}-\mathrm{WO}_{3}-\mathrm{Na}_{2} \mathrm{O}-$ $\mathrm{Nb}_{2} \mathrm{O}_{5}-\mathrm{Al}_{2} \mathrm{O}_{3}$ glass fibres", J. Lumin. 134, 528-532 (2013).

22. V. Scarnera, B. Richards, A. Jha, G. Jose, and C. Stacey, "Green up-conversion in $\mathrm{Yb}^{3+}-\mathrm{Tb}^{3+}$ and $\mathrm{Yb}^{3+}-\mathrm{Tm}^{3+}-\mathrm{Tb}^{3+}$ doped fluoro-germanate bulk glass and fibre", Opt. Mater. 33, 159-163 (2010).
23. A. Zajac, D. Dorosz, M. Kochanowicz, M. Skórczakowski, and J, Swiderski, "Fibre lasers - conditioning constructional and technological", Bull. Pol. Acad. Sci. Tech. Sci. 58, 491-502 (2010).

24. M. Kochanowicz, J. Zmojda, P. Miluski, J. Pisarska, W.A. Pisarski, and D. Dorosz, "NIR to visible up-conversion in double - clad optical fibre co-doped with $\mathrm{Yb}^{3+} / \mathrm{Ho}^{3+"}$, Opt . Mater. Express 5, 1505-1510 (2015). 